\title{
Peran Pendidikan dalam Meningkatkan Minat Pemuda untuk Melanjutkan Usaha Tani di Daerah Konservasi DAS Solo Hulu
}

\author{
Nandhika Murti Azhari $^{1 *}$, Sapja Anantanyu', Eksa Rusdiyana1 \\ ${ }^{1}$ Program Studi Penyuluhan dan Komunikasi Pertanian, Fakultas Petanian, \\ Universitas Sebelas Maret \\ *Corresponding author: nandhikama123@student.uns.ac.id
}

\begin{abstract}
Abstrak
Tenaga kerja muda pertanian di Daerah Aliran Sungai (DAS) Solo Hulu jumlahnya sangat sedikit dibandingkan dengan tenaga kerja pertanian golongan tua, maka diperlukan berbagai upaya guna meningkatkan minat pemuda untuk bekerja di bidang pertanian di daerah konservasi DAS Solo Hulu. Pendidikan merupakan salah satu faktor yang cukup berpengaruh dalam menentukan minat pemuda pada sektor pertanian. Penelitian ini bertujuan untuk mengetahui peran pendidikan dalam meningkatkan minat pemuda untuk melanjutkan usaha tani di daerah konservasi DAS Solo Hulu yang meliputi pendidikan formal, informal, dan non formal. Metode penelitian yang digunakan adalah metode deskriptif dengan pendekatan kualitatif. Penentuan lokasi dilakukan secara purposive dan penentuan informan dilakukan secara purposive sampling kepada 10 informan. Metode analisis data yang digunakan adalah Analysis Interactive Model Miles dan Huberman. Pengujian keabsahan data menggunakan uji kepercayaan dengan triangulasi sumber dan metode. Hasil penelitian menunjukkan bahwa pendidikan terbagi menjadi pendidikan formal, informal, dan non formal. Peran pendidikan formal tidak memberikan pengaruh dalam meningkatkan minat pemuda untuk melanjutkan usaha tani. Peran pendidikan informal lingkungan memberikan pengaruh dalam meningkatkan minat pemuda untuk melanjutkan usaha tani. Sedangkan peran pendidikan non formal memberikan pengaruh dalam meningkatkan minat pemuda untuk melanjutkan usaha tani. Kesimpulan dari penelitian ini adalah peran pendidikan informal lingkungan dan pendidikan non formal mempunyai pengaruh sangat penting dalam meningkatkan minat pemuda untuk melanjutkan usaha tani di daerah konservasi DAS Solo Hulu.
\end{abstract}

Kata kunci: Pendidikan formal, Pendidikan informal, Pendidikan non formal

\begin{abstract}
The number of young agricultural workers in the Solo Hulu watershed is very small. Various efforts are needed to increase the interest of the young generation to work in the agricultural sector at the Solo Hulu watershed conservation area. Education is one of the most influential factors in determining youth interest in the agricultural sector. This study aims to determine the role of education in increasing the interest of the young generation to continue the agricultural business in the Solo Hulu watershed conservation area. The research used a descriptive method with a qualitative approach. The location was determined by purposive method and also the informants was determined by purposive sampling to 10 informants. The data analysis uses the Miles and Huberman Interactive Model Analysis. To test the validity of the data is using a credibility test with triangulation of sources and methods. The results showed that education was divided into formal, informal, and non-formal education. The formal education has no effect in increasing the interest of the young generation to continue the agricultural business. The environmental informal education has an influence in increasing the interest of the young generation to continue the agricultural business. While the role of non-formal education has an influence in increasing the interest of the young generation to continue the agricultural business. The conclusion is that the role of environmental informal education and non-formal education has a very important influence in increasing the interest of youth to continue agricultural business in the Solo Hulu watershed conservation area.
\end{abstract}

Keywords: Formal education, Informal education, Non-formal education 
Prosiding Seminar Nasional Pembangunan dan Pendidikan Vokasi Pertanian

Politeknik Pembangunan Pertanian Manokwari, 31 Juli 2021

e ISSN : 2774-1982

DOI : https://doi.org/10.47687/snppvp.v2i1.180

\section{PENDAHULUAN}

Indonesia merupakan negara agraris yang sebagian besar penduduknya bermatapencaharian sebagai petani. Badan Pusat Statistik (BPS) menyebut bahwa jumlah penduduk yang bekerja per Agustus 2020 sebanyak 128,45 juta orang, dari angka tersebut, terbanyak bekerja di sektor pertanian dengan 38,23 juta tenaga kerja atau sekitar 29,76\% (Annur, 2020). Meskipun peran tenaga kerja pertanian Indonesia memiliki kontribusi terbesar dalam penyerapan tenaga kerja nasional, namun sampai saat ini Indonesia masih dihadapkan pada permasalahan serius di bidang ketenagakerjaannya yaitu perubahan struktur demografi yang kurang menguntungkan, diantaranya petani berusia tua (lebih dari 55 tahun) jumlahnya semakin meningkat, sementara petani berusia muda semakin menurun (Susilowati, 2016).

Pendidikan merupakan salah satu faktor yang cukup berpengaruh dalam menentukan minat pemuda pada sektor pertanian (Sari et al., 2017). Jalur pendidikan sesuai pasal 13 ayat 1 UU tahun 2003 tentang Sistem Pendidikan Nasional, terbagi menjadi 3, yakni jalur pendidikan formal, pendidikan non formal, dan pendidikan informal. Pendidikan formal adalah jalur pendidikan yang terstruktur dan berjenjang yang terdiri atas pendidikan dasar, pendidikan menengah, dan pendidikan tinggi. Pendidikan informal adalah jalur pendidikan keluarga dan lingkungan. Pendidikan non formal adalah jalur pendidikan di luar pendidikan formal yang dapat dilaksanakan secara terstruktur dan berjenjang (Wibowo, 2019).

Penelitian Meliasari et al. (2017) menyatakan bahwa pemuda yang memiliki tingkat pendidikan tinggi tidak akan memilih pertanian untuk bidang pekerjaannya. Selanjutnya Maryani et al. (2020) juga menyatakan bahwa kurikulum pendidikan kurang menekankan pengenalan dunia pertanian dan lingkungan sehingga anak-anak Indonesia kurang memiliki minat untuk mengembangkan pertanian di negaranya. Penelitian terdahulu dari Hoffmann et al. (2015) menyatakan bahwa orang tua berperan penting dalam mengarahkan pilihan profesi atau pekerjaan anaknya di masa depan. Selain itu, penelitian dari Muslim (2017) mengatakan bahwa lingkungan masyarakat tidak memberi kontribusi nyata terhadap minat pemuda berusahatani. Teori dari Crow dalam Khairani (2013) menyatakan bahwa semakin banyak pengalaman yang diperoleh oleh petani, maka minat mereka terhadap usaha tani semakin tinggi. Penelitian dari Ningsih et al. (2019) mengungkap bahwa akses informasi mempengaruhi keterlibatan pemuda dalam pertanian, 
Prosiding Seminar Nasional Pembangunan dan Pendidikan Vokasi Pertanian

Politeknik Pembangunan Pertanian Manokwari, 31 Juli 2021

e ISSN : 2774-1982

DOI : https://doi.org/10.47687/snppvp.v2i1.180

semakin tinggi akses pemuda terhadap informasi pertanian maka akan semakin besar pengaruhnya terhadap keterlibatan pemuda pada pertanian di pedesaan

Berdasarkan data Keadaan Angkatan Kerja di Kabupaten Karanganyar 2019, bahwa tenaga kerja di bidang pertanian sebanyak 95.346 jiwa. Berdasarkan angka tersebut didominasi tenaga kerja dengan kelompok umur lebih dari 60 tahun sebanyak 35.787 jiwa (37,53\%), 50-59 tahun sebanyak 28.862 jiwa (30,27\%), 40-49 tahun sebanyak 12.381 jiwa (12,98\%), 30-39 tahun sebanyak 11.305 jiwa (11,85\%), 20-29 tahun sebanyak 6.443 jiwa (6,75\%). Sedangkan kelompok umur 15-19 tahun merupakan kelompok umur tenaga kerja pertanian paling sedikit yaitu sebanyak 568 jiwa $(0,59 \%)$ (BPS, 2020). Hal tersebut menunjukkan bahwa semakin berkurangnya tenaga kerja muda di sektor pertanian di Kabupaten Karanganyar.

Desa Beruk, Kecamatan Jatiyoso, Kabupaten Karanganyar merupakan bagian dari Daerah Aliran Sungai (DAS) Bengawan Solo Hulu dan termasuk dalam sub DAS Jlantah-Walikan. Kawasan Desa Beruk mempunyai kemiringan lereng yang paling sempit yaitu lereng kelas V (> 45\%) atau sangat curam dengan luas 388,59 ha (Hidayat, 2012). Lahan pertaniannya adalah tanah kering dengan jenis tanah andosol. Saat melakukan kegiatan usaha tani di lahan yang miring perlu adanya pemahaman terkait dengan prinsipprinsip konservasi untuk tetap menjaga kelestarian lingkungan supaya dapat memberikan keuntungan secara ekonomi bagi manusia. Mata pencaharian pemuda terbanyak adalah wiraswasta sebesar 47,14\%, sedangkan pemuda yang menjadi petani hanya $8,8 \%$. Mayoritas tingkat pendidikan pemuda adalah tamatan SD sebesar 44,82\% dan SMP sebesar 38,61\%. Berdasarkan hal tersebut menunjukkan bahwa tenaga kerja muda pertanian di Desa Beruk jumlahnya masih sangat sedikit dan tingkat pendidikan pemuda masih rendah. Berdasarkan pemaparan tersebut maka penelitian ini bertujuan untuk mengetahui peran pendidikan dalam meningkatkan minat pemuda untuk melanjutkan usaha tani di daerah konservasi DAS Solo Hulu yang terbagi dalam pendidikan formal, informal, dan non formal.

\section{METODE}

Metode penelitian yang digunakan dalam penelitian ini adalah metode deskriptif dengan pendekatan kualitatif. Penentuan lokasi dilakukan secara sengaja (purposive) yaitu di Desa Beruk, Kecamatan Jatiyoso, Kabupaten Karanganyar yang merupakan bagian dari DAS Bengawan Solo Hulu dan mempunyai kemiringan lereng sangat curam. Penentuan informan dilakukan secara purposive sampling untuk mendapatkan 10 
Prosiding Seminar Nasional Pembangunan dan Pendidikan Vokasi Pertanian

Politeknik Pembangunan Pertanian Manokwari, 31 Juli 2021

e ISSN : 2774-1982

DOI : https://doi.org/10.47687/snppvp.v2i1.180

informan yang terbagi dalam informan kunci (ketua karang taruna), informan utama (pemuda yang berusia 20-40 tahun), dan informan pendukung (orang tua, guru SD, perangkat desa). Penelitian dilakukan dalam waktu 10 bulan, mulai bulan Agustus 2020 sampai Mei 2021 yang dimulai dengan observasi awal dan diakhiri dengan penyusunan dan analisis data. Jenis data yang digunakan adalah kuantitatif dan kualitatif, dengan sumber data primer dan sekunder. Teknik pengumpulan data dilakukan dengan cara observasi, wawancara mendalam, dan dokumentasi. Teknik analisis data menggunakan Analysis Interactive Model dari Miles dan Huberman yang terdiri dari reduksi data, penyajian data, penarikan kesimpulan dan verifikasi. Pengujian keabsahan data dalam penelitian ini dilakukan dengan uji kepercayaan yang menggunakan triangulasi sumber dan metode. Triangulasi sumber dilakukan dengan cara mengecek data yang telah diperoleh melalui beberapa sumber. Data yang diperoleh dianalisis kemudian menghasilkan suatu kesimpulan selanjutnya dimintakan kesepakatan (member check) dengan tiga sumber data. Sedangkan, triangulasi metode dilakukan dengan cara mengecek data kepada sumber yang sama dengan teknik yang berbeda. Teknik yang digunakan yaitu melalui wawancara, observasi, dan dokumentasi.

\section{HASIL DAN PEMBAHASAN}

Berdasarkan data pada Rekapitulasi Pencarian Penduduk Desa Beruk sampai Juni 2021 diketahui bahwa jumlah pemuda yang berusia 20-40 tahun di Desa Beruk sebanyak 1.419 jiwa. Jumlah pemuda laki-laki yaitu 715 jiwa (50,38\%) dan pemuda perempuan sebesar 704 jiwa (49,62\%). Selanjutnya mayoritas tingkat pendidikan pemuda di Desa Beruk hanya sampai tamatan SD yaitu sebesar 636 jiwa $(44,82 \%)$ dan disusul dengan tamatan SMP sebanyak 548 jiwa $(38,61 \%)$. Mata pencaharian utama pemuda yang terbanyak adalah wiraswasta sebanyak 669 jiwa (47,14\%), sedangkan pemuda yang menjadikan petani sebagai pekerjaan utama jumlahnya hanya sedikit yaitu hanya 125 jiwa $(8,8 \%)$.

Pemuda di Desa Beruk dalam penelitian ini terbagi menjadi dua yaitu pemuda tani dan pemuda bukan tani. Pemuda tani merupakan pemuda yang berusia 20-40 tahun yang saat ini menjadikan pekerjaan petani sebagai pekerjaan utama maupun sampingan. Sedangkan pemuda bukan tani merupakan pemuda yang berusia 20-40 tahun yang saat ini tidak menjadikan pekerjaan petani sebagai pekerjaan utama maupun sampingan. Pemuda tani dalam penelitian ini banyak ditemukan di Dusun Ngantirejo dan Pengkok. Sedangkan pemuda bukan tani banyak ditemukan di selain kedua dusun tersebut yaitu di Dusun 
Prosiding Seminar Nasional Pembangunan dan Pendidikan Vokasi Pertanian

Politeknik Pembangunan Pertanian Manokwari, 31 Juli 2021

e ISSN : 2774-1982

DOI : https://doi.org/10.47687/snppvp.v2i1.180

Turus, Selangkah, Beruk Kulon, Beruk Wetan, Kambangan, Pringombo, dan Gunung Lading. Dikarenakan penelitian ini sudah dilakukan pengamatan di lapangan secara langsung, maka dalam penelitian ini faktor pembentuk minat pemuda untuk melanjutkan usaha tani di daerah konservasi DAS Solo Hulu yaitu pendidikan yang terdiri dari beberapa jalur yaitu pendidikan formal, informal, dan non formal.

\section{Pendidikan Formal}

Minat pemuda untuk melanjutkan usaha tani dalam penelitian ini dapat terjadi karena pendidikan formal yang terdiri dari tingkat pendidikan dan akses pembelajaran pertanian. Tingkat pendidikan maksudnya adalah pendidikan terakhir yang ditempuh pemuda. Sedangkan akses pembelajaran pertanian yaitu pembelajaran pertanian yang di dapatkan oleh pemuda ketika mereka menempuh sekolah dasar.

Desa Beruk mempunyai akses pendidikan formal yang terdiri dari 2 Sekolah Dasar (SD N 01 Beruk dan SD N 03 Beruk), 1 Sekolah Menengah Pertama (SMP N 4 Jatiyoso), dan 1 Sekolah Menengah Atas (MA Terpadu Darul Amal). Pemuda Desa Beruk mayoritas tamatan dari beberapa sekolah tersebut. Walaupun akses pendidikan sudah tersedia, namun mayoritas pemuda hanya sampai tamatan sekolah dasar. Hal ini dikarenakan SMP dan MA yang tersedia baru berdiri sekitar 15 tahun terakhir. Sehingga dimungkinkan banyak pemuda yang berusia 30 tahun ke atas yang mengalami keterbatasan ketersediaan akses pendidikan. Tabel 1 menunjukkan perbedaan tingkat pendidikan pemuda di Desa Beruk.

Tabel 1. Tingkat Pendidikan Pemuda di Desa Beruk

\begin{tabular}{lccc}
\hline \hline Tingkat Pendidikan & $\begin{array}{c}\text { Pemuda Pekerjaan } \\
\text { Utama Petani }\end{array}$ & $\begin{array}{c}\text { Pemuda Pekerjaan Utama } \\
\text { di Luar Sektor Pertanian }\end{array}$ & Jumlah \\
\hline Tamat SD/Sederajat & 114 & 492 & 636 \\
Tamat SLTP/Sederajat & 9 & 539 & 548 \\
Tamat SLTA/Sederajat & 2 & 128 & 130 \\
\hline Jumlah & 125 & 1.159 & 1.314 \\
\hline
\end{tabular}

Sumber: Rekapitulasi Pencarian Penduduk sampai Juni 2021

Berdasarkan tabel 1 menunjukkan tingkat pendidikan pemuda yang menjadikan petani sebagai pekerjaan utama lebih rendah jika dibandingkan dengan pemuda yang pekerjaan utamanya di luar sektor pertanian. Setelah pemuda menempuh jalur pendidikan formal, bagi pemuda yang tidak ingin melanjutkan pendidikan ke jenjang yang lebih tinggi, mereka langsung terjun pada dunia kerja, ada yang bekerja di sektor pertanian dan non pertanian. Pemuda tamatan SD mayoritas lebih memilih untuk bertani, jika tidak 
Prosiding Seminar Nasional Pembangunan dan Pendidikan Vokasi Pertanian

Politeknik Pembangunan Pertanian Manokwari, 31 Juli 2021

e ISSN : 2774-1982

DOI : https://doi.org/10.47687/snppvp.v2i1.180

ingin bertani pemuda memilih merantau. Lalu pemuda yang tamat SMA lebih memilih mencari pekerjaan lain di luar sektor pertanian maupun melanjutkan kuliah.

Walaupun tingkat pendidikan pemuda yang pekerjaan utamanya di luar sektor pertanian jauh lebih tinggi dibandingkan dengan pemuda yang pekerjaan utamanya petani namun berdasarkan hasil observasi dan wawancara, banyak ditemukan pemuda yang pekerjaan utamanya di luar sektor pertanian dan sudah berkeluarga menjadikan pekerjaan petani sebagai pekerjaan sampingan. Khususnya pemuda yang bertempat tinggal di Dusun Ngantirejo dan Pengkok. Meskipun pemuda mempunyai pendidikan yang tinggi hingga SMA maupun Sarjana, pemuda masih terjun langsung melakukan kegiatan usaha tani.

Penelitian ini berbeda dengan penelitian Meliasari et al. (2017) yang menyatakan bahwa pemuda yang memiliki tingkat pendidikan tinggi tidak akan memilih pertanian untuk bidang pekerjaannya. Sedangkan pada penelitian ini masih banyak ditemukan pemuda yang berpendidikan tinggi yang menjadikan pekerjaan petani sebagai pekerjaan sampingan dan pemuda yang berpendidikan rendah memilih pekerjaan lain di luar sektor pertanian yang dikarenakan bertani bukan bagian dari passion mereka. Sehingga dalam hal ini, tingkat pendidikan pemuda di Desa Beruk tidak berpengaruh terhadap minat pemuda untuk melanjutkan usaha tani.

Pemuda di Desa Beruk sudah menerima pembelajaran terkait dengan pertanian sejak duduk di bangku sekolah dasar (SD). Kegiatan tersebut berupa bercocok tanam di sekolah serta tugas untuk mengikuti orang tua pergi ke lahan. Guru yang ada di Desa Beruk memahami betul bahwa mayoritas siswanya dari latar belakang keluarga petani sehingga pembelajaran tersebut perlu dilakukan dengan tujuan ketika mereka sudah lulus sekolah apabila tidak melanjutkan ke jenjang yang lebih tinggi, mereka dapat membantu orang tua dalam bertani.

Penelitian ini berbeda dengan penelitian terdahulu dari Maryani et al. (2020) yang menyatakan bahwa kurikulum pendidikan yang menjadi pedoman pengajaran pada anak kurang menekankan pengenalan dunia pertanian dan lingkungan sehingga anak-anak Indonesia kurang memiliki minat untuk mengembangkan pertanian di negaranya. Sedangkan dalam penelitian ini walaupun pembelajaran pertanian tidak masuk dalam kurikulum, namun tetap disisipkan lewat pembelajaran praktik secara langsung. Namun hasilnya tidak memberikan pengaruh pada minat pemuda untuk melanjutkan usaha tani terbukti dengan masih terdapat pemuda yang lebih memilih pekerjaan di luar sektor 
Prosiding Seminar Nasional Pembangunan dan Pendidikan Vokasi Pertanian

Politeknik Pembangunan Pertanian Manokwari, 31 Juli 2021

e ISSN : 2774-1982

DOI : https://doi.org/10.47687/snppvp.v2i1.180

pertanian. Sehingga dalam hal ini, akses pembelajaran pertanian pada pendidikan formal tidak berpengaruh terhadap minat pemuda untuk melanjutkan usaha tani.

\section{Pendidikan Informal}

Pendidikan informal dalam penelitian ini maksudnya pembelajaran pertanian yang didapatkan oleh pemuda dari keluarga dan lingkungan. Pemuda di Desa Beruk mayoritas menerima pembelajaran bertani dari pihak keluarga yaitu kedua orang tua. Pembelajaran bertani dilakukan secara bertahap dengan cara saat kecil pemuda diajak pergi ke lahan walaupun hanya sekedar bermain-main, namun lama-lama pemuda dapat mengamati pekerjaan orang tua, sehingga dapat menirukan kegiatan tersebut. Selain itu, dalam hal pemilihan pekerjaan di sektor pertanian maupun non pertanian pemuda tidak bergantung pada keputusan orang tua, karena orang tua menuruti pilihan anaknya dan hanya berperan memberikan saran yang terbaik untuk anaknya.

Penelitian ini berbeda dengan penelitian terdahulu dari Hoffmann et al. (2015) yang menyatakan bahwa orang tua berperan penting dalam mengarahkan pilihan profesi atau pekerjaan anaknya di masa depan. Sedangkan dalam penelitian ini, peran keluarga tidak begitu berpengaruh terhadap keputusan pemuda untuk melanjutkan usaha tani. Hal ini dikarenakan pemuda mempunyai keinginan sendiri untuk bekerja di sektor pertanian maupun non pertanian. Pemuda akan menentukan sendiri jenis pekerjaan apa yang cocok dengan passionnya. Selain itu, walaupun orang tua sudah mengajarkan pembelajaran bertani sejak usia dini namun masih terdapat pemuda yang memiliki minat rendah untuk melanjutkan usaha tani.

Pendidikan informal lingkungan dalam penelitian ini berarti pembelajaran pertanian yang didapatkan pemuda dari lingkungan di sekitar pemuda yang terdiri dari lingkungan sosial dan lingkungan tempat tinggal. Lingkungan sosial berkaitan dengan organisasi yang diikuti pemuda dan pergaulan pemuda. Tabel 2 menunjukkan perbedaan lingkungan antara pemuda tani dan pemuda bukan tani di Desa Beruk.

Tabel 2. Perbedaan Lingkungan Pemuda Desa Beruk

\begin{tabular}{lll}
\hline \hline \multicolumn{1}{c}{ Aspek } & \multicolumn{1}{c}{ Pemuda Tani } & \multicolumn{2}{c}{ Pemuda Bukan Tani } \\
\hline Keanggotaan organisasi & Karang taruna & Karang taruna \\
Lingkungan pertemanan & Banyak teman sebaya & Banyak teman sebaya yang \\
di tempat tinggal & yang bekerja sebagai & bekerja sebagai pedagang, \\
& petani & perantau, dan buruh bangunan \\
Lingkungan tempat & Banyak tetangga yang & Banyak tetangga yang \\
melakukan kegiatan & melakukan kegiatan berdagang \\
tinggal & usaha tani & \\
& &
\end{tabular}

Sumber: Analisis Data Primer, 2021 
Prosiding Seminar Nasional Pembangunan dan Pendidikan Vokasi Pertanian

Politeknik Pembangunan Pertanian Manokwari, 31 Juli 2021

e ISSN : 2774-1982

DOI : https://doi.org/10.47687/snppvp.v2i1.180

Berdasarkan tabel 2 tersebut diketahui bahwa organisasi kepemudaan yang diikuti pemuda adalah karang taruna. Desa Beruk memiliki karang taruna yang terbagi dalam tingkat RT, dusun, dan desa. Mayoritas pemuda mengikuti karang taruna tingkat RT dan dusun. Semakin banyak organisasi kepemudaan yang diikuti maka semakin banyak pula teman pergaulan yang dimiliki pemuda. Pemuda yang memilih pekerjaan di luar sektor pertanian pada umumnya dipengaruhi oleh teman-teman sebayanya yang banyak bekerja di luar sektor pertanian, seperti pedagang sayur dan buruh bangunan. Pemuda yang memilih bekerja di sektor pertanian karena teman di area tempat tinggalnya banyak yang menjadi petani. Selain itu, lingkungan tempat tinggal pemuda tani banyak ditemukan tetangga yang bekerja di sektor pertanian dan aktivitas kegiatan usaha tani. Sedangkan lingkungan tempat tinggal pemuda bukan tani banyak ditemukan tetangga pemuda bukan tani yang bekerja di luar sektor pertanian yaitu pedagang sayur keliling.

Penelitian ini tidak mendukung hasil penelitian dari Muslim (2017) yang mengatakan bahwa lingkungan masyarakat tidak memberi kontribusi nyata terhadap minat pemuda berusahatani. Pada kenyataannya dalam penelitian ini semakin banyak lingkungan pemuda dikelilingi dengan pekerjaan yang berkaitan dengan pertanian maka minat pemuda untuk melanjutkan usaha tani juga semakin tinggi. Namun jika lingkungan pemuda dikelilingi dengan lingkungan pekerjaan di luar sektor pertanian maka pemuda memiliki minat yang rendah untuk melanjutkan usaha tani.

\section{Pendidikan Non Formal}

Menurut Prasetya (2019) bahwa pendidikan non formal bagi petani diperoleh dari penyuluhan dan sosialisasi yang dilakukan oleh lembaga penyuluhan pertanian maupun dari lembaga pertanian lainnya. Maka pendidikan non formal dalam penelitian ini yaitu pendidikan pertanian yang didapatkan pemuda melalui sosialisasi maupun pelatihan yang terbagi dalam pengalaman bekerja di sektor pertanian dan akses informasi pertanian. Pengalaman bekerja di sektor pertanian maksudnya seberapa lama pemuda bekerja di bidang pertanian. Tabel 3 menunjukkan perbedaan pengalaman bekerja di sektor pertanian pemuda di Desa Beruk. 
Prosiding Seminar Nasional Pembangunan dan Pendidikan Vokasi Pertanian Politeknik Pembangunan Pertanian Manokwari, 31 Juli 2021

e ISSN : 2774-1982

DOI : https://doi.org/10.47687/snppvp.v2i1.180

Tabel 3. Perbedaan Pengalaman Bekerja di Sektor Pertanian Pemuda Desa Beruk

\begin{tabular}{lll}
\hline \multicolumn{1}{c}{ Aspek } & \multicolumn{1}{c}{ Pemuda Tani } & \multicolumn{1}{c}{ Pemuda Bukan Tani } \\
\hline $\begin{array}{l}\text { Lama bekerja di } \\
\text { sektor pertanian }\end{array}$ & Lebih dari 10 tahun & Kurang dari 5 tahun \\
$\begin{array}{l}\text { Lama bekerja di luar } \\
\text { sektor pertanian }\end{array}$ & Kurang dari 5 tahun & Lebih dari 5 tahun \\
$\begin{array}{l}\text { Bentuk pekerjaan } \\
\text { Persiapan, penanaman, } \\
\text { perawatan, pemanenan }\end{array}$ & $\begin{array}{l}\text { Membantu } \\
\text { membawakan pupuk dan hasil } \\
\text { panen }\end{array}$ \\
\hline Sumber pengalaman & Dari orang tua & Dari orang tua \\
\hline
\end{tabular}
Sumber: Analisis Data Primer, 2021

Berdasarkan tabel 3 tersebut dapat diketahui bahwa pemuda tani di Desa Beruk memiliki pengalaman bekerja di sektor pertanian lebih banyak dibandingkan pemuda bukan tani. Pemuda mendapatkan pengalaman tersebut bukan berasal dari sosialisasi maupun penyuluhan dari penyuluh pertanian, namun dari keluarga secara turun temurun melalui kegiatan membantu usaha tani di keluarga. Hal tersebut dikarenakan kelompok tani maupun penyuluh pertanian yang ada tidak aktif dalam memberikan penyuluhan pertanian. Beralihnya pekerjaan pemuda bekerja dari sektor pertanian ke non pertanian dikarenakan pemuda hanya mempunyai sedikit pengalaman di bidang pertanian dan hasil yang didapatkan dari pekerjaan di luar sektor petanian lebih pasti. Sedangkan beralihnya pekerjaan pemuda dari sektor non pertanian ke sektor pertanian dikarenakan pemuda mengalami kegagalan ketika bekerja di luar sektor pertanian seperti bangkrut atau tidak sukses saat merantau.

Penelitian ini mendukung teori dari Crow dalam Khairani (2013) yang menyatakan bahwa semakin banyak pengalaman yang diperoleh oleh petani, maka minat mereka terhadap usaha tani semakin tinggi. Hal tersebut juga berlaku dalam penelitian ini bahwa pengalaman yang dimiliki pemuda di sektor pertanian berpengaruh terhadap minat pemuda untuk melanjutkan usaha tani. Pemuda yang mempunyai pengalaman banyak dalam bertani pada akhirnya akan memilih untuk melanjutkan usaha tani, sedangkan pemuda yang mempunyai pengalaman sedikit dalam bertani akan memilih pekerjaan di luar sektor pertanian sehingga memiliki minat yang rendah untuk melanjutkan usaha tani.

Maksud dari akses informasi pertanian dalam penelitian ini yaitu informasiinformasi apa saja yang didapatkan oleh pemuda seputar dengan pertanian. Tabel 4 menunjukkan perbedaan akses informasi pertanian pemuda di Desa Beruk. 
Prosiding Seminar Nasional Pembangunan dan Pendidikan Vokasi Pertanian

Politeknik Pembangunan Pertanian Manokwari, 31 Juli 2021

e ISSN : 2774-1982

DOI : https://doi.org/10.47687/snppvp.v2i1.180

Tabel 4 Perbedaan Akses Informasi Pertanian Pemuda

\begin{tabular}{lll}
\hline \multicolumn{1}{c}{ Aspek } & \multicolumn{1}{c}{ Pemuda Tani } & Pemuda Bukan Tani \\
\hline Sumber informasi pertanian & $\begin{array}{l}\text { Teman sesama petani, } \\
\text { ilmu titen, pedagang }\end{array}$ & Pedagang \\
$\begin{array}{l}\text { Intensitas mengakses informasi } \\
\text { pertanian melalui internet }\end{array}$ & Jarang & Sangat jarang \\
Informasi pertanian yang dicari & $\begin{array}{l}\text { Perawatan budidaya, } \\
\text { harga hasil pertanian }\end{array}$ & Harga hasil pertanian \\
\hline
\end{tabular}

Sumber: Analisis Data Primer, 2021

Berdasarkan tabel 4 tersebut dapat disimpulkan bahwa pemuda di Desa Beruk tidak mendapatkan informasi terkait dengan pertanian melalui penyuluh pertanian maupun dari kelompok tani melainkan dari ilmu titen, teman sesama petani, dan pedagang, namun sebagian ada juga yang mengakses informasi lewat internet. Sedangkan pemuda bukan tani biasanya mengakses informasi pertanian hanya seputar dengan harga hasil pertanian, namun pemuda tani mengakses informasi terkait dengan budidaya pertanian. Maka dalam hal ini ketersediaan akses informasi memberikan pengaruh terhadap minat pemuda untuk melanjutkan usaha tani.

Penelitian ini mendukung penelitian dari Ningsih et al. (2019) yang menyatakan bahwa akses informasi mempengaruhi keterlibatan pemuda dalam pertanian, semakin tinggi akses pemuda terhadap informasi pertanian, maka akan semakin besar pengaruhnya terhadap keterlibatan pemuda pada pertanian di pedesaan. Hal tersebut berlaku juga pada penelitian ini yaitu semakin pemuda memiliki minat yang tinggi untuk melanjutkan usaha tani maka semakin tinggi juga pemuda mencari informasi terkait dengan pertanian.

\section{KESIMPULAN DAN SARAN}

Kesimpulan dari penelitian yang sudah dilakukan yaitu pendidikan mempunyai pengaruh dalam pembentukan minat pemuda untuk melanjutkan usaha tani di daerah konservasi DAS Solo Hulu. Peran pendidikan formal tidak berpengaruh dalam meningkatkan minat pemuda untuk melanjutkan usaha tani. Peran pendidikan informal lingkungan berpengaruh dalam meningkatkan minat pemuda untuk melanjutkan usaha tani. Serta peran pendidikan non formal juga berpengaruh dalam meningkatkan minat pemuda untuk melanjutkan usaha tani. Berdasarkan hasil penelitian tersebut, maka diharapkan Pemerintah Desa Beruk dapat mendorong kelompok tani yang ada untuk berperan aktif dalam melakukan pengoptimalan kelembagaan petani dengan meningkatkan peran pemuda di sektor pertanian melalui berbagai bentuk kegiatan maupun program, serta dapat mendorong organisasi kepemudaan yang ada untuk 
Prosiding Seminar Nasional Pembangunan dan Pendidikan Vokasi Pertanian

Politeknik Pembangunan Pertanian Manokwari, 31 Juli 2021

e ISSN : 2774-1982

DOI : https://doi.org/10.47687/snppvp.v2i1.180

disisipkan kegiatan yang berhubungan dengan pertanian. Selain itu, penyuluh pertanian setempat supaya berperan aktif dalam melakukan penyuluhan maupun pelatihan di kelompok tani yang ada di Desa Beruk dengan melibatkan pemuda supaya dapat menjadi penyedia informasi terkait dengan pertanian.

\section{DAFTAR PUSTAKA}

Annur, C. M. (2020). Sektor Pertanian Paling Banyak Menyerap Tenaga Kerja Indonesia. https://databoks.katadata.co.id.

Badan Pusat Statistik. (2020). Keadaan Angkatan Kerja di Kabupaten Karanganyar 2019. Karanganyar: BPS.

Hidayat, M. (2012). Evaluasi Kesesuaian Fungsi Kawasan Dan Konservasi Lahan Daerah Aliran Sungai Walikan Kabupaten Karanganyar dan Kabupaten Wonogiri. Skripsi. Universitas Sebelas Maret, Surakarta.

Hoffmann, A., Junge, M., \& Malchow-Moller, N. (2015). Running in the Family: Parental Role Models in Entrepreneurship. Journal of Small Business Economics, 44(1), 79-104.

Khairani, H. M. (2013). Psikolog Belajar. Yogyakarta: Aswaja Persindo.

Maryani, A. T., \& Nyimas, M. E. F. (2020). Pengenalan dan Penanaman Tanaman SayurSayuran pada Tk Pertiwi Xi Kecamatan Pelayanagan Kota Jambi. https://doi.org/10.31219/osf.io/rj3mx.

Meliasari, Endriatmo, S., \& Mohammad, S. (2017). Hubungan Kondisi Sosial-Ekonomi Rumah Tangga dengan Minat Pemuda Desa di Bidang Pertanian (Desa Mulangsari, Kecamatan Pangkalan, Kabupaten Karawang). Jurnal Sains Komunikasi dan Pengembangan Masyarakat, 1(4), 523-53.

Muslim, M. (2017). Pengaruh Persepsi tentang Status Sosial Ekonomi dan Lingkungan Petani terhadap Minat Berusahatani Padi : Kasus Pemuda Desa Ciwalen, Warungkondang, Cianjur, Jawa Barat. Skripsi. Universitas Islam Negeri Syarif Hidayatullah, Jakarta.

Ningsih, F., \& Sofyan, S. (2015). Faktor-Faktor yang Menentukan Keterlibatan Pemuda Pedesaan pada Kegiatan Pertanian Berkelanjutan. Jurnal Penyuluhan, 11(1), 2338.

Prasetya, N. R. (2019). Hubungan Tingkat Pendidikan dan Umur Petani dengan Penurunan Jumlah Rumah Tangga Usaha Pertanian Sub Sektor Tanaman Pangan di Desa Meteseh Kecamatan Boja Kabupaten Kendal. Skripsi. Universitas Negeri Semarang, Semarang.

Rekapitulasi Pencarian Penduduk Desa Beruk Kecamatan Jatiyoso Kabupaten Karanganyar 2021. (2021). Desa Beruk.

Sari, M. P., Igusti, P. B. S. A., \& Gede, K. (2017). Pergeseran Pekerjaan Remaja dari Sektor Pertanian ke Sektor Industri. Jurnal Ilmiah Sosiologi, 1(1), 1-13. 
Prosiding Seminar Nasional Pembangunan dan Pendidikan Vokasi Pertanian

Politeknik Pembangunan Pertanian Manokwari, 31 Juli 2021

e ISSN : 2774-1982

DOI : https://doi.org/10.47687/snppvp.v2i1.180

Susilowati, S. H. (2016). Fenomena Penuaan Petani dan Berkurangnya Tenaga Kerja Muda Serta Implikasinya Bagi Kebijakan Pembangunan Pertanian. Forum Penelitian Agro Ekonomi, 34(1), 35-55.

Wibowo, A. (2019). Pengawasan Pendidikan Formal untuk Meningkatkan Kualitas Sumber Daya Manusia Perbatasan di Kabupaten Sanggau. Jurnal Ilmu Hukum, 3(1), 23-39. 